\title{
High precision validation of micro injection molding process simulations
}

\author{
Tosello, G.; Costa, F. S.
}

Published in:

Journal of Manufacturing Processes

Link to article, DOI:

10.1016/j.jmapro.2019.10.014

Publication date:

2019

Document Version

Peer reviewed version

Link back to DTU Orbit

Citation (APA):

Tosello, G., \& Costa, F. S. (2019). High precision validation of micro injection molding process simulations. Journal of Manufacturing Processes, 48, 236-248. https://doi.org/10.1016/j.jmapro.2019.10.014

\section{General rights}

Copyright and moral rights for the publications made accessible in the public portal are retained by the authors and/or other copyright owners and it is a condition of accessing publications that users recognise and abide by the legal requirements associated with these rights.

- Users may download and print one copy of any publication from the public portal for the purpose of private study or research.

- You may not further distribute the material or use it for any profit-making activity or commercial gain

- You may freely distribute the URL identifying the publication in the public portal

If you believe that this document breaches copyright please contact us providing details, and we will remove access to the work immediately and investigate your claim. 
See discussions, stats, and author profiles for this publication at: https://www.researchgate.net/publication/337312839

\section{High Precision Validation of Micro Injection Molding Process Simulations}

Article in Journal of Manufacturing Processes · November 2019

DOI: 10.1016/j.jmapro.2019.10.014

CITATIONS

4

2 authors:

a Guido Tosello

2. Technical University of Denmark 218 PUBLICATIONS 1,182 CITATIONS

SEE PROFILE
READS

446

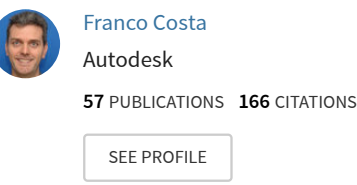

Some of the authors of this publication are also working on these related projects:

Molded Pulp Products Manufacturing: Process Development, Characterization and Modeling View project

Green Fiber Bottle project View project 


\title{
High Precision Validation of Micro Injection Molding Process Simulations
}

\author{
G. Tosello ${ }^{1 *}$, F. S. Costa ${ }^{2}$
}

${ }^{1}$ Department of Mechanical Engineering, Technical University of Denmark, Building 427A, Produktionstorvet, DK-2800 Kgs. Lyngby, Denmark

${ }^{2}$ Autodesk Inc, Moldflow R\&D Center, 259-261 Colchester Road, Kilsyth, Australia

*Corresponding author: quto@mek.dtu.dk

\begin{abstract}
Simulation of the micro injection molding $(\mu \mathrm{IM})$ process is a powerful tool to perform product, tool and process design in the early stages of the development of polymer micro components. However, the necessary precision needed to exploit the advantages of process simulation is challenging the software simulation technology. High accuracy $\mu \mathrm{IM}$ process control is a key aspect when performing micro molding simulations. Hence, data analysis and simulations of $\mu \mathrm{IM}$ experiments have been conducted. Micro molding simulations have been executed by implementing in the software the actual processing conditions.

Various aspects of the simulation set-up have been considered in order to improve the simulation accuracy (i.e. to decrease deviations from experimental values): injection speed profile, pressure at injection location, melt and mold temperatures, three-dimensional mesh parameters, and material rheological characterization. Quality factors investigated for the quantitative comparisons were: short shot length, injection pressure profile, molding mass and flow pattern.

Inconsistencies and uncertainties in the experimental data must be minimized to avoid introducing uncertainties in the simulation calculations. In this work, simulations of bulky sub-100 milligrams micro molded parts have been validated. A methodology for accurate micro molding simulations is proposed and established.
\end{abstract}




\section{Introduction}

Simulation programs of polymer micro injection molding $(\mu \mathrm{M})$ are applied for the same reasons as for conventional injection molding: To avoid the risks of costly re-engineering, the manufacturing process is simulated before part and mold designs are finalized. Optimization of the molding process and of the tool using simulation techniques can lead to significant cost savings in tooling and production trials. Therefore, in polymer micro manufacturing technology, software simulation tools adapted from conventional injection molding can provide useful assistance for the optimization of molding tools, mold inserts, micro component designs, and process parameters. In order to obtain reliable results, adapted simulations of micro molding applications need to be validated by comparison with experimental results. Due to the miniaturized scale of the part and the extreme conditions of the process, accurate process monitoring is challenging and therefore software validation is affected by the availability of adequately precise experimental data.

A proper implementation strategy employed during the set-up of the simulation can greatly improve the quality (i.e. the accuracy) of the simulated results. During this research, an extensive experimental database (based on actual micro injection molding experiments) has been established in order to carry out a comparative study with simulation results. Simulations were carried out using a commercially available software package and their implementation was performed applying calibrated input data collected during the micro injection molding process. Results were compared in a quantitative study using performance indicators such as flow front position (i.e. short shot length), injection pressure profile, molding mass and flow pattern shape.

Validation of simulation software is an essential step in order to assess the capability of the implemented mathematical model to predict the actual process dynamics. In order to validate the polymer flow (i.e. filling) simulation in $\mu \mathrm{IM}$, different approaches can be employed: a micro cavity partially filled in subsequent steps (the so-called short shot method) [1][2][3], flow-melt visualization method using a in-cavity high speed camera [4][5][6], the use of flow marker positions to trace the evolution of the flow front [7][8], the comparison of process parameters levels sampled during the process (i.e. injection pressure).

Validation studies in the area of micro-injection molding are complicated by three additional factors: $i$ the difficulty of sensor placement within the reduced dimensions of the mold and molding cavity since the smallest cavity sensors available have a minimum diameter of $1 \mathrm{~mm}$;

$\ddot{l}$ the high speed of the molding process that could produce shear rates beyond the validity of capillary rheometry data (i.e. shear rates in the order of $10^{6}-10^{7} 1 / \mathrm{s}$, especially at gate position);

i the potential for altered physics due to the smaller part feature and molding machine size.

Placement of sensors such as pressure sensors will often not be possible in the reduced dimensions of the molding cavity and so alternative locations for the sensors must be employed. For example, the pressure transducers may be located in the feed system, where larger dimensions than the cavity exist, but this means that direct validation of cavity pressure values predicted by simulation is not possible.

Timing of data acquisition and the accuracy of these recordings become important in the high injection speeds used for micro molding.

Numerous approximations traditionally made for conventional injection molding simulation may become invalid for micro molding. One example of this is the heat transfer coefficient used to model 
the heat flux across the interface of the polymer and mold metal. Values typically used in conventional injection molding are derived from experiments performed on typical cavity thicknesses above $1 \mathrm{~mm}$ [9]. These heat transfer coefficient values may not be appropriate in a simulation of the packing phase of micro-injection molding; usually a constant heat transfer coefficient (HTC) is assumed, but it cannot describe the flow through micro channels and its standard value suitable for simulation of macro parts differs substantially from values indicated for $\mu \mathrm{IM}$ [8][10][11]. Different HTC values can affect the flow length of simulated micro molded parts and consequently by using a reverse engineering approach it is possible to establish a correlation with the experimental moldings [12]. Nevertheless, it appears that an experimental validation of HTC values based on heat transfer measurements in micro injection molding is currently not available.

Moreover, one of the main limitations encountered in micro molding simulations relates to the fact that rheological data used in current packages are obtained from macroscopic experiments and that a no-slip boundary condition is employed with the consequence that wall slip cannot be predicted [10]. On the other hand, even though laboratory equipment for high speed rheometry tests has been developed [13][14][15], standardized micro capillary rheology testing equipment and procedures are currently not available. Experimental investigations have shown the presence of typical phenomena induced by high processing speed and downscaled dimensions such as: wall slip on polymer melt flow in micro scaled channels and its influence on viscosity [16]; the appearance of a Newtonian plateau approximately at shear rates in the order of $10^{6} 1 / \mathrm{s}$; a shear thickening effect appearing at shear rates close to $10^{7} 1 / \mathrm{s}$. Nevertheless, rheological models suitable for software implementation are far from being formulated and are therefore currently not available. Moreover, surface tension, neglected in macro molding, plays a role on the filling of micro structures but is not taken into account in currently available simulation tools [17].

Another approximation typically used is that part width and length are much larger than the part thickness, and so shell based solutions techniques can be used. These shell based solutions employ the Hele-Shaw assumptions to simplify the computation domain and reduce the time and cost of computation. According to the Hele-Shaw assumptions, the pressure is assumed to be uniform through the part thickness, the flow resistance due to drag on the cavity edges is neglected, thermal convection is neglected in the thickness direction and thermal conduction is neglected in all directions except for the thickness direction [18][19]. However, such Hele-Shaw assumptions are not valid for micro molding parts which more typically have length and width scales similar to their thickness scales. Indeed, larger discrepancies of $\mu \mathrm{IM}$ simulation results when using Hele-Shaw assumption as compared with full three-dimensional calculations have been already reported [8]. As a consequence, the use of a true three-dimensional simulation models is preferred and has been employed in the present research work.

As it appears from the recent research performed in the field of $\mu \mathrm{IM}$ simulation, inconsistencies and uncertainties in the micro molding data available so far still exist, and simulated results are currently still affected by those inaccuracies. As a consequence, it is not possible to perform reliable benchmark comparisons to justify changes in models formulation, solution methods as well as coefficients or quantities in the implemented models. The current situation has instead motivated the present research in order to better understand $\mu \mathrm{IM}$ experiments accuracy and its role in the validation of $\mu \mathrm{IM}$ simulations. For this reason, a quantitative approach to process monitoring was applied to obtain both $\mu \mathrm{IM}$ process and product calibrated measurements. For each 
process/product related measurand an average value obtained from repeated measurements using calibrated instrumentation was obtained, and for each averaged result a measure of its repeatability was associated. The accurate process calibration was performed both to provide quality input data for simulation set-up and to obtain reliable output data for results validation. Consequently, a meaningful comparison can be performed between the simulation and experimental results.

The accuracy of the simulation results depends on many component technologies and information. The short shot method was applied in the present research work, with process quantities (pressure, speed, temperature, stroke length) and product characteristics (weight, flow front length, flow pattern shape) monitored at different stages of the filling phase.

\section{Micro injection molding experiments}

The possibility to accurately produce micro plastic parts depends on the availability of high accuracy micro injection machines, optimized molding processes and high precision micro tools. For the purpose of this study, a micro molding machine (FormicaPlast 1k, i.e. one-component, from DESMAtec), provided with a two-plunger plasticizing/injection unit (see Figure 1a), was employed during the experiments (injection piston diameter $=3 \mathrm{~mm}$, plasticizing piston diameter $=6 \mathrm{~mm}$ ) [7]. The injection chamber always has a total available stroke length of $23 \mathrm{~mm}$, irrespective of the programmed shot size. Closed-loop mold and temperature controls were implemented as indicated in Figure $1 b$.

The mold was a two cavity dog-bone tensile bar molding as shown in Figure 2, with a part thickness of $1 \mathrm{~mm}$, width ranging from $1.5 \mathrm{~mm}$ to $3 \mathrm{~mm}$ and a part length of $12 \mathrm{~mm}$. The whole molding including the miniaturized sprue, two runners and two parts had a weight of $91.3 \mathrm{mg}$ (with a standard deviation of $0.3 \mathrm{mg}$ on a sample of 10 parts randomly selected over 50 parts). The molding experiments were performed using a BASF Ultraform H2320 004 POM material. The material viscosity was determined using a capillary rheometer to verify the accuracy of the material characteristics in the software database (see Figure 3). Eventually, correspondence between viscosity data of the employed polymer and its rheology characterization present in the software database was demonstrated.

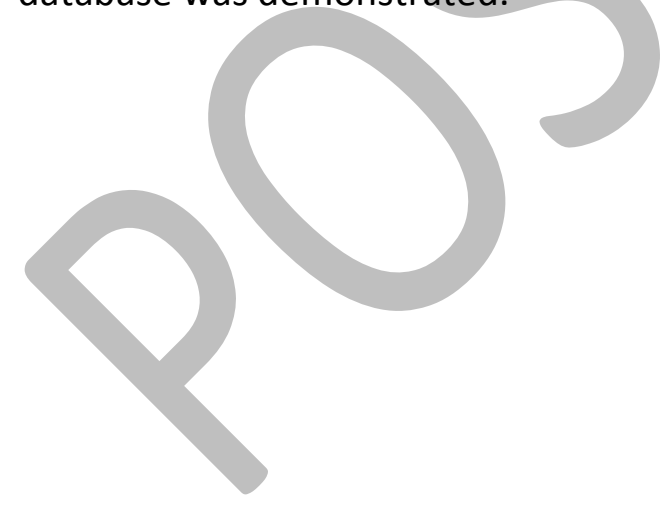




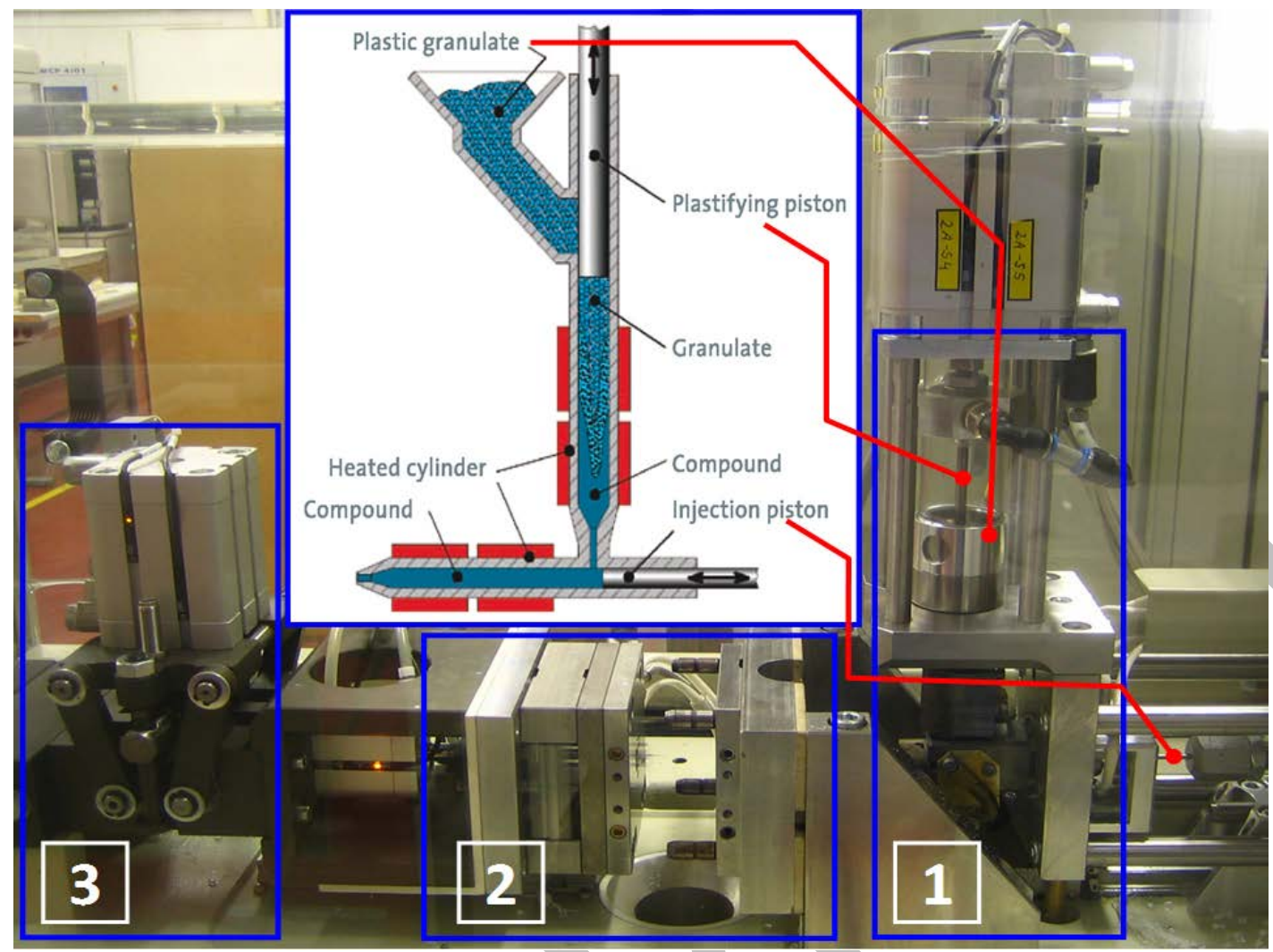

(a)

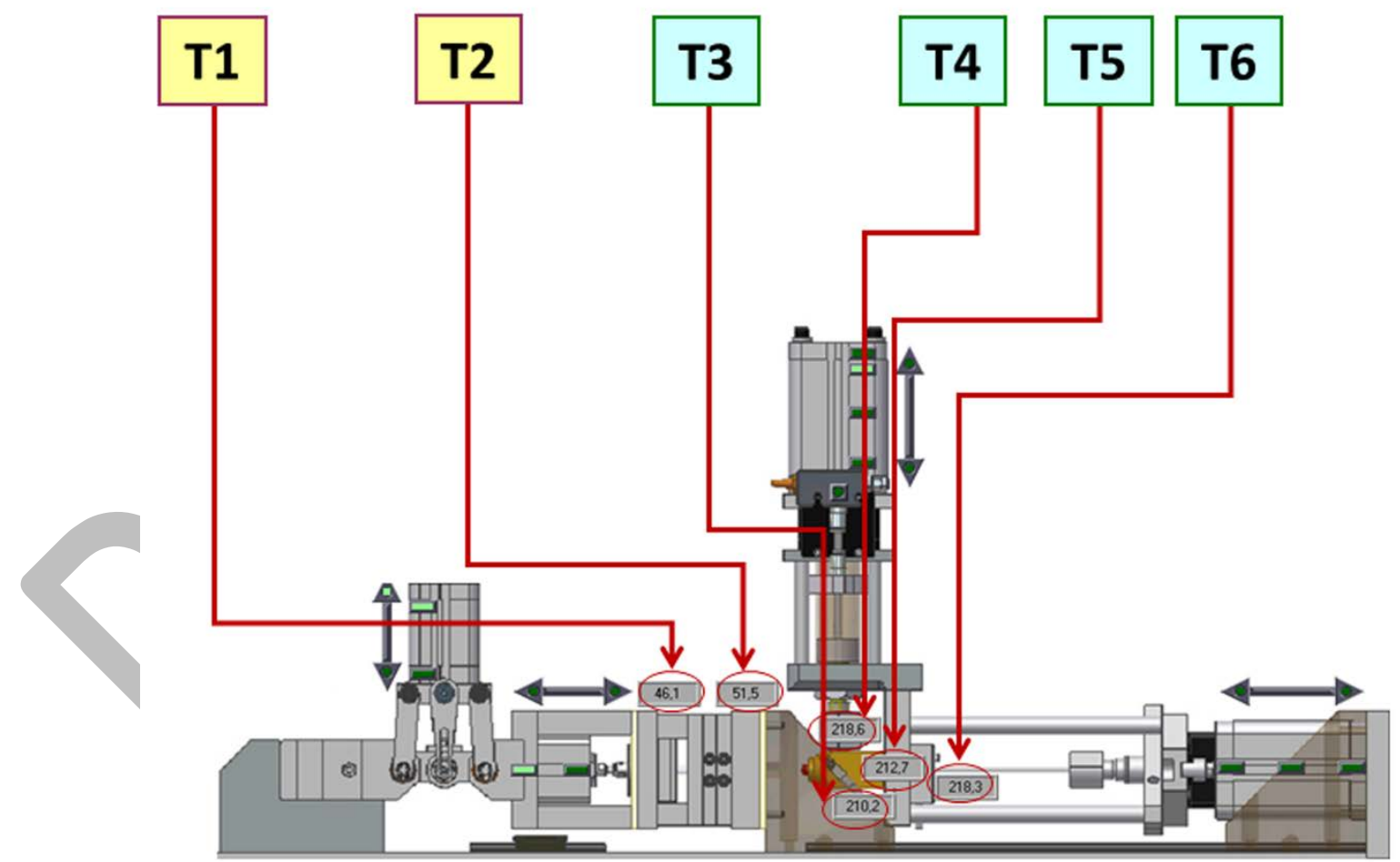

(b)

Figure 1 - (a) Two stage (plasticizing and injection) unit (1), micro mold (2) and pneumatic toggle clamping unit (3) of the employed micro injection molding machine; (b) positions of mold temperature control (T1, T2) and melt temperature control (T3, T4, T5, T6). 


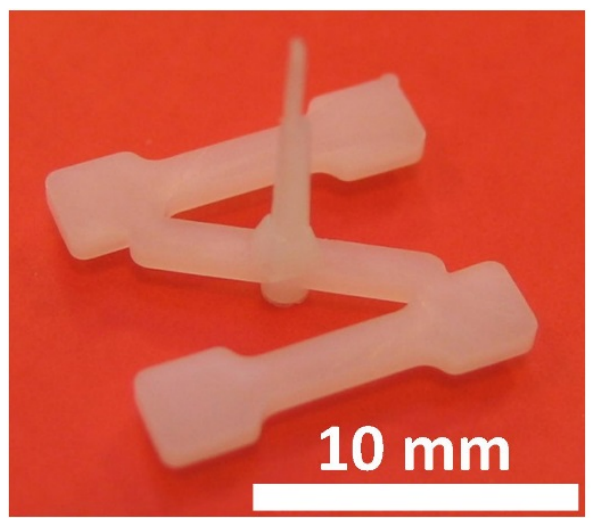

Figure 2 - Two-cavity dog-bone tensile bar micro molded part (material: POM).

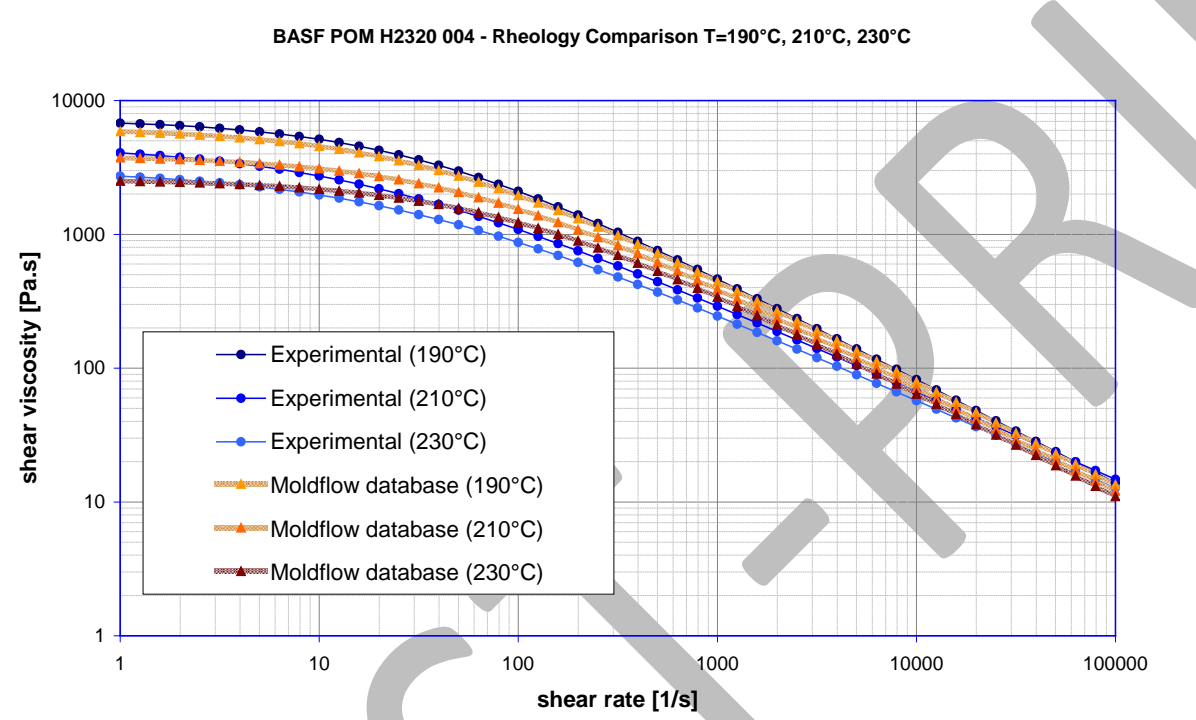

Figure 3 - Experimental comparison of rheological data of material BASF POM H2320 003 between experimental results obtained by capillary rheometry and Autodesk Moldflow ${ }^{\circledR}$ database.

\subsection{Process and part control}

The molding procedure was conducted as a continuous process with automated part ejection operated by miniaturized mechanical pins. Molding of production batches included first a temperature stabilization time of about 10 minutes, then a molding series of 25 parts followed by an actual series of 50 parts suitable for process and part analysis. Process data was automatically collected by in-built sensors in the machine for each molding cycle and included: shot stroke length, injection speed, injection pressure, mold temperature on both sides of the mold and melt temperature in four different locations of the injection unit (injection nozzle, end of dosing chamber, middle and beginning injection chamber) (see Figure $1 \mathrm{~b}$ ).

Measured mold temperatures were $51.8 \pm 0.3{ }^{\circ} \mathrm{C}$ at the injection plate (i.e. fixed mold side) and $45.0 \pm 0.1^{\circ} \mathrm{C}$ at the ejection plate (i.e. moving mold side). Melt temperature was set at $220^{\circ} \mathrm{C}$ and measured at $223.7 \pm 0.1^{\circ} \mathrm{C}$ at the nozzle location. 
Piston position and speed were measured for 12 different stroke lengths: $1,2,3,4,5,6,7,8,9,10$, $11,12 \mathrm{~mm}$. The injection profile was set with a constant speed of $100 \mathrm{~mm} / \mathrm{s}$ for all piston stroke lengths. The injection piston diameter was $3 \mathrm{~mm}$.

Piston positions could be repeated within an average deviation from nominal values of $16 \mu \mathrm{m}$ over the whole piston stroke and a sampling range of 20 cycles (see Figure 4) for each stroke length setting. Position repeatability between 1 and $11 \mu \mathrm{m}$ was observed which corresponds to a mass repeatability of injected melt better than $0.1 \mathrm{mg}$.

The average injection speed was measured at $99.7 \mathrm{~mm} / \mathrm{s}$ with a standard deviation of $1.1 \mathrm{~mm} / \mathrm{s}$ over the whole $12 \mathrm{~mm}$ range of piston stroke lengths and a production batch of 20 cycles (see Figure 5) for each stroke length setting. As a result, injection time for a complete molding was $120 \pm 1 \mathrm{~ms}$. After dosing of polymer melt from the plastifying chamber to the injection chamber, a $3 \mathrm{~mm}$ decompression movement is applied to the injection piston. This decompression is used to allow the piston to accelerate for a stroke length of $3 \mathrm{~mm}$ prior to the actual start of the melt injection in order to be able to provide the requested speed at the beginning of the full length stroke (i.e. at injection piston position $=0 \mathrm{~mm}$ ).

The piston followed the set speed profile for a prescribed stroke length until the point of switchover to the packing phase. During the experiments, a zero packing pressure was applied and the cooling time was $3 \mathrm{~s}$. Total cycle time was $7.36 \mathrm{~s}$, with a repeatability error (i.e. standard deviation) lower than $10 \mathrm{~ms}$ on the whole cycle time.

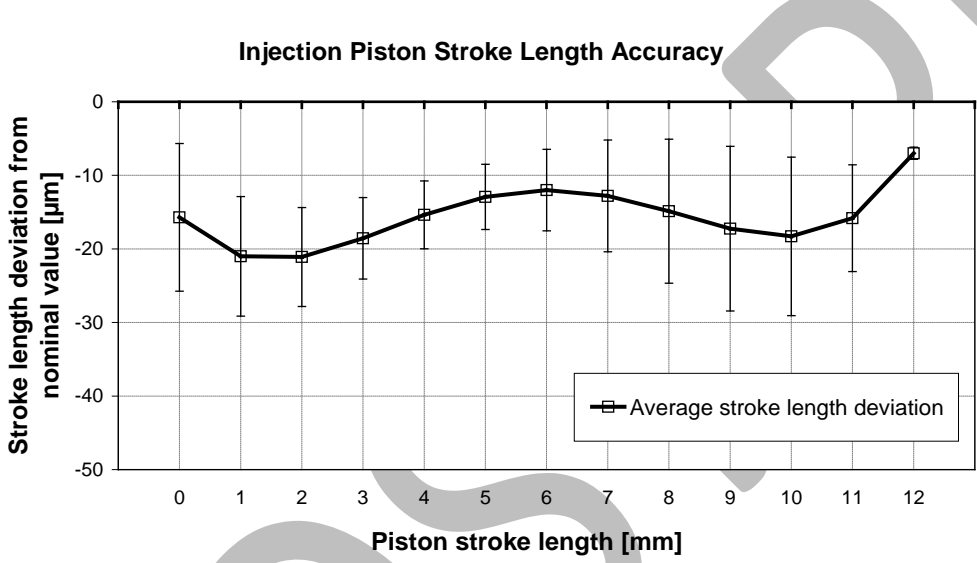

Figure 4 - Machine calibration in terms of piston position precision and accuracy (average and standard deviation of a sample of 20 molding cycles).

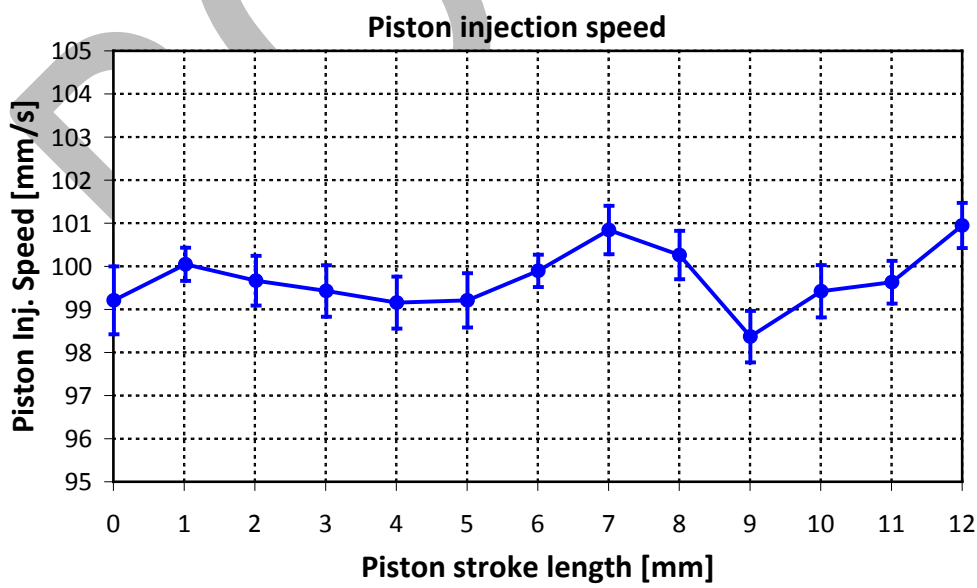

Figure $\mathbf{5}$ - Injection speed profile over the range of stroke lengths (average and standard deviation of a sample of 20 molding cycles). 


\subsection{Flow advancement experimental study using the short shot method}

Intermediate filling stages and product repeatability were characterized by means of measuring part mass and length for a series of short shot molding trials. Process resolution and repeatability was proven to be a function of the stroke length, with relative variation of both length and mass decreasing towards complete filling (see Figure 6 and Figure 7). Although the short shot molded parts had a mass repeatable in the range of 0.1 to $0.4 \mathrm{mg}$, repeatability of dimensional values was in the range of few tens of micrometers. This demonstrates the difficulty of producing highly repeatable parts with micrometer precision when molding short shots with weights of tens of milligrams at high injection speed and thus the difficulty to actually use these results for micro molding simulation validation.

The short shot length (L) was defined as part length along the main flow direction in the dog-bone section of the molding and it was measured with a calibrated optical coordinate measuring machine (measuring uncertainty $= \pm 2 \mu \mathrm{m}$ ) (see Figure 8).

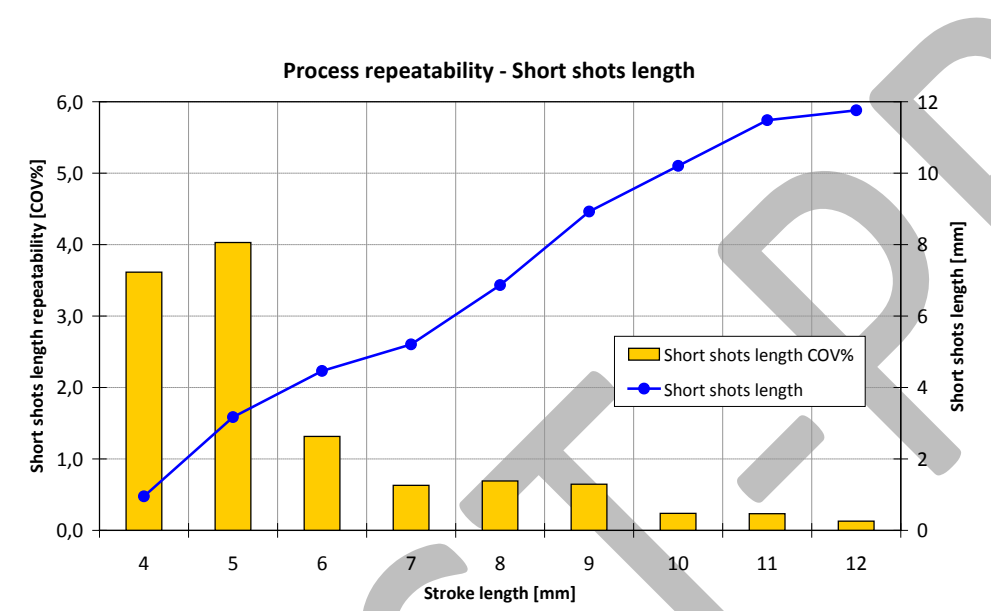

Figure 6 - Micro injection molding process characterization: short shot length and relative repeatability (COV\% = standard deviation at a given stroke / average short shot length).

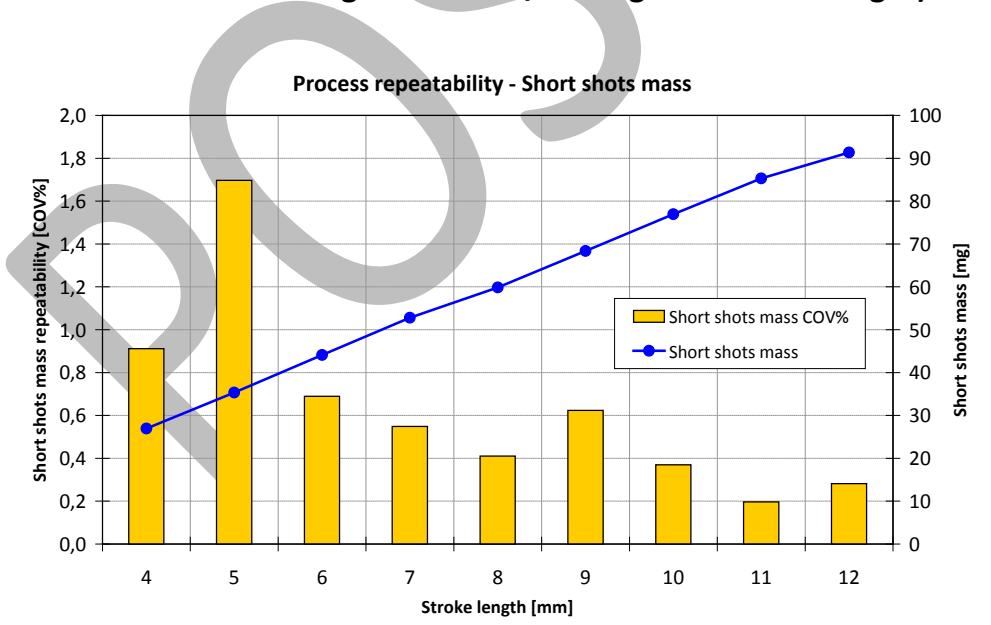

Figure 7 - Micro injection molding process characterization: short shots mass and relative repeatability (COV\% = standard deviation at a given stroke length / average short shot mass). 


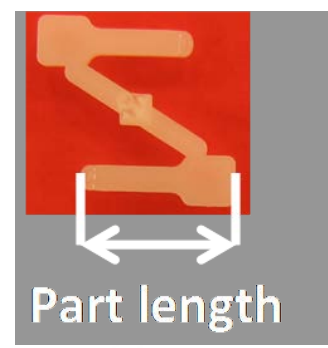

$5 \mathrm{~mm}$

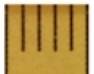

Figure 8 - Short shot characterization: definition of the flow length measurement.

\subsection{Indirect injection pressure measurement: the air shot method}

An important molding process parameter to be used for comparison between experiments and simulations is the injection pressure. However, injection pressure must be exactly defined and monitored in order to be able to actually validate simulated results. The employed micro molding machine is able to automatically record the pressure applied to the melt by the piston during the injection phase. The pressure is indirectly measured by the machine control based on the current usage of the servo-drive system in order to achieve the requested piston injection speed.

Based on this definition, the pressure monitored by the machine is the so-called piston injection pressure. On the other hand, the simulation software is calculating the injection pressure at the injection location in the simulation model (see Figure 9). Hence, in order to predict the piston injection pressure, the nozzle geometry must be known and included in the simulation, as reported in [20] for injection molding simulations of conventionally-sized components. This is a mandatory requirement because a small difference in nozzle dimensions and geometry has a dramatic influence on the injection pressure and therefore on the validation of simulated pressure results. This influence was proved by means of simulations of three different nozzles configurations, modelled as hot-runners elements, applied to the considered miniaturized dog bone geometry: (A) $0.85 \mathrm{~mm}$ and (B) $0.40 \mathrm{~mm}$ nozzle diameter with taper from the $3 \mathrm{~mm}$ injection chamber, and (C) $0.40 \mathrm{~mm}$ diameter with no taper (see Figure 10). Depending on the considered geometry, the predicted injection pressure is heavily affected with variations between $100 \%$ and $250 \%$. Also, it was observed that the simulated injection pressure with all these hypothetical nozzle dimensions were lower than the measured piston injection pressures (see Figure 11).

Due to such high sensitivity of the predicted injection pressure to nozzle geometry and the unavailability of actual nozzle dimension information, the injection pressure at the sprue tip (see detail in Figure 9), was selected as the process output parameter for comparison between the simulations and the experimental results. Using the injection pressure at the sprue tip allows the injection pressure to be simulated based only on the known cavity geometry (i.e. not influenced by the unknown nozzle geometry). During the molding experiments, a method based on the air shot technique was applied to determine the actual cavity injection pressure at the sprue tip. 


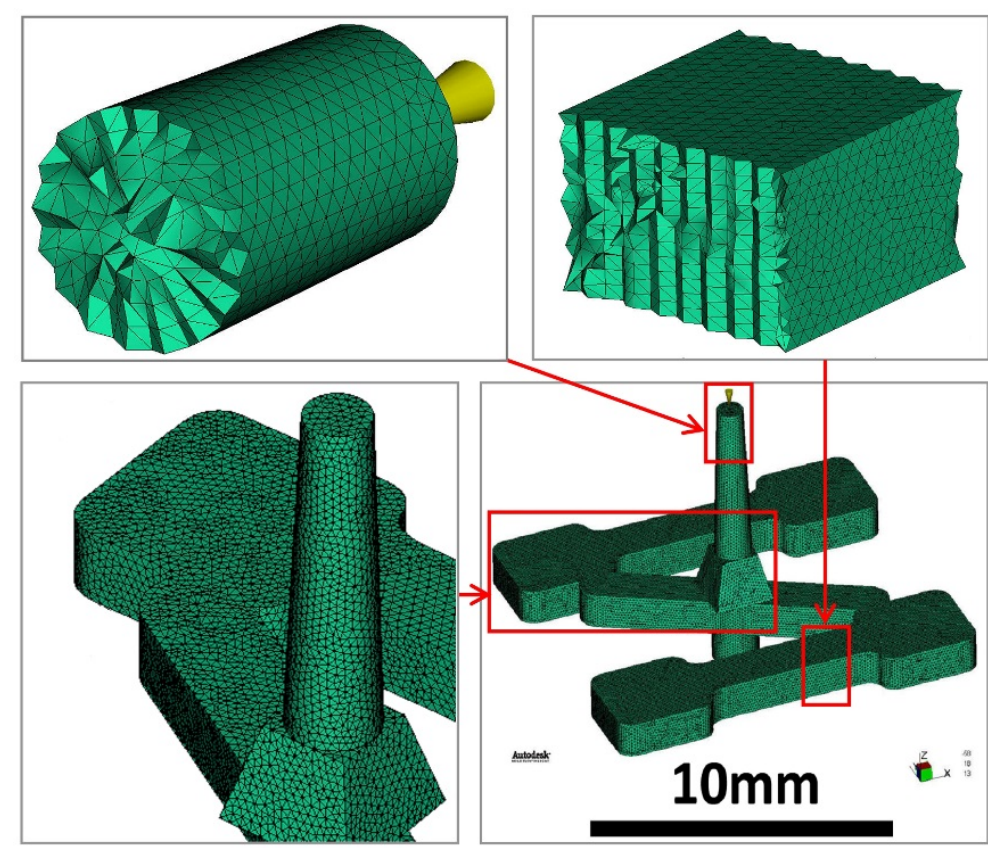

Figure 9 - Three-dimensional mesh model (the injection location is visible on top of the sprue tip, sprue tip diameter $=800 \mu \mathrm{m})$.

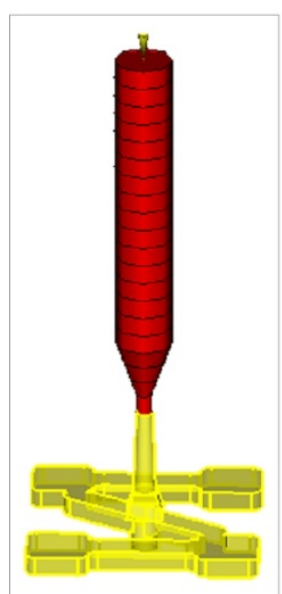

A

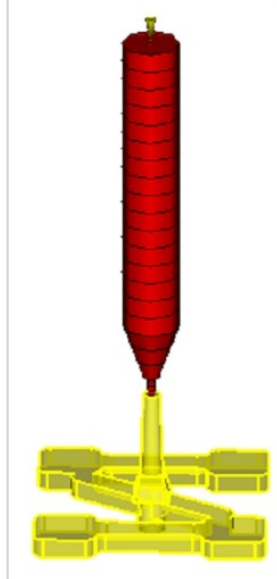

B

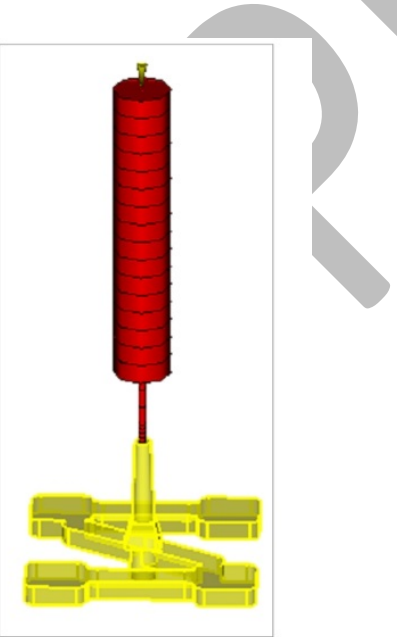

C

Figure 10 - Hypothetical nozzle tips for dog-bone cavity: (A) $0.85 \mathrm{~mm}$ diameter with taper, (B) 0.4 mm diameter with taper, and (C) $0.4 \mathrm{~mm}$ diameter with no taper. Injection chamber (i.e. barrel) diameter is $3 \mathrm{~mm}$. 

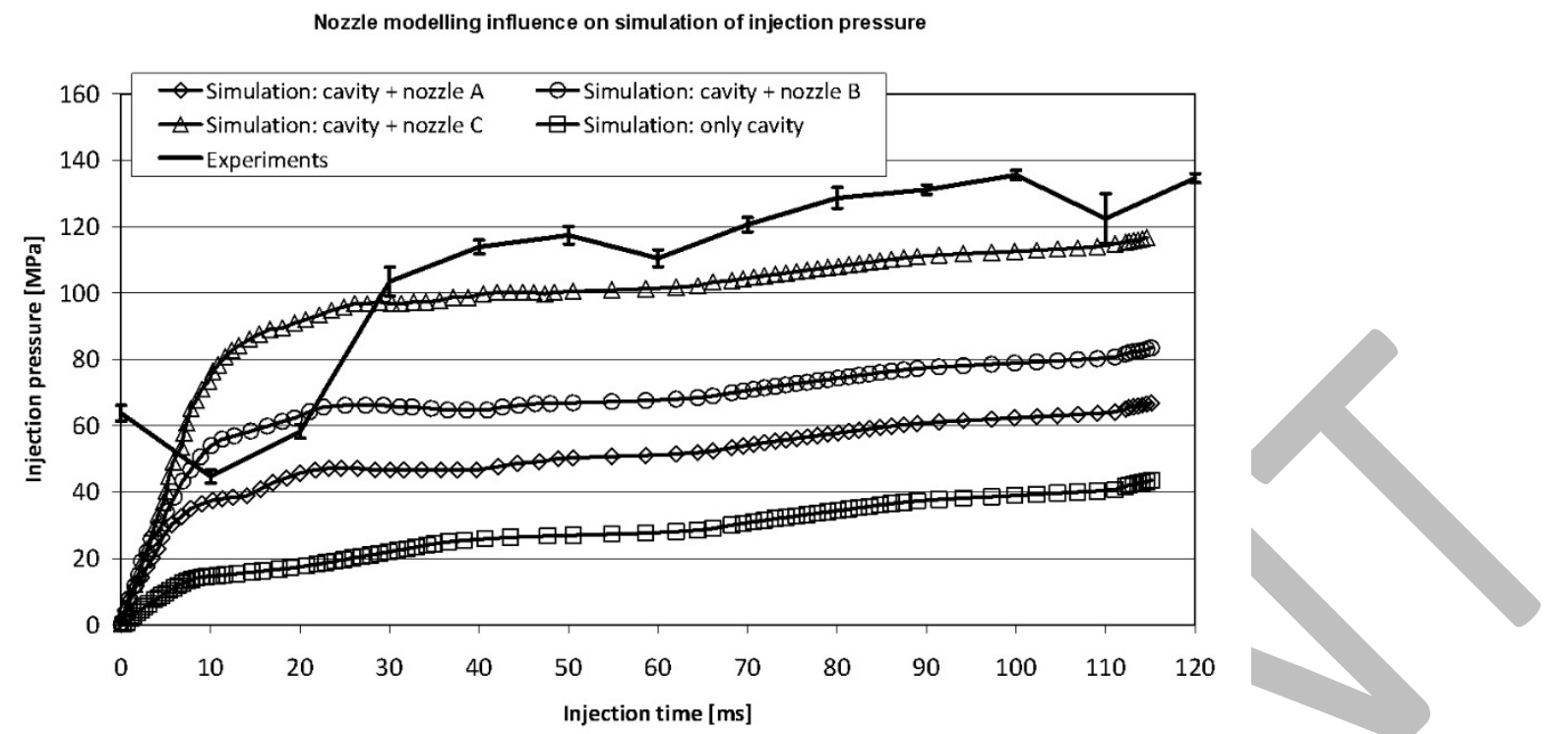

Figure 11 - Predicted injection pressure from four variations of dog-bone molding with different injection nozzles.

The air shot method consisted of a series of short shot moldings (executed at 1, 2, 3, 4, 5, 6, 7, 8, 9, $10,11,12 \mathrm{~mm}$ stroke length) performed with the mold open, using the same injection speed as had been used in the previous closed mold short shot moldings. In this way, the piston injection pressure measured by the machine can only be affected by the injection chamber, the nozzle geometry and the sprue. A typical extrudate which results from an air shot molding is shown in Figure 12. Examination of these air shot extrudates revealed that the polymer did not form consistent contact with the sprue geometry. Rather it appears that at the selected injection speed, the polymer has jetted from the nozzle tip during the air shot trials and did not initially form a viscous flow in the sprue despite the presence of the tapered sprue geometry. Therefore, it is considered that the piston injection pressure measured by the machine during the air shot trials is only the pressure required to flow through the injection chamber and nozzle geometry. The difference between the piston injection pressure with the mold open (i.e. air shot experiments) and the mold closed (i.e. short shot experiments) will be the pressure drop in the sprue, runners and part cavities (see Figure 13). It is important to use this sprue tip pressure for a reliable comparison of experiment and simulation when the simulation model does not include the nozzle geometry. Repeatability of the cavity (sprue tip) injection pressure was derived from the repeatability (i.e. the standard deviation) of both short shot and air shot injection pressure applying the general law of error propagation [21]. Process control procedures were also applied in the case of piston injection pressure monitoring for both short shots and air shots (average and standard deviation of at least 10 cycles were calculated). In addition, to ensure quality of the air shot experiments, mass was measured and average and standard deviation of at least 10 moldings were calculated. An air shot mass average standard deviation of $2.6 \mathrm{mg}$ was found. 


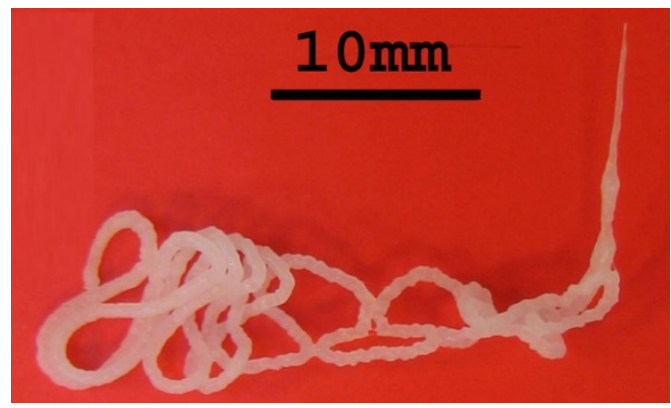

Figure 12 - Air shot molding (material: POM).

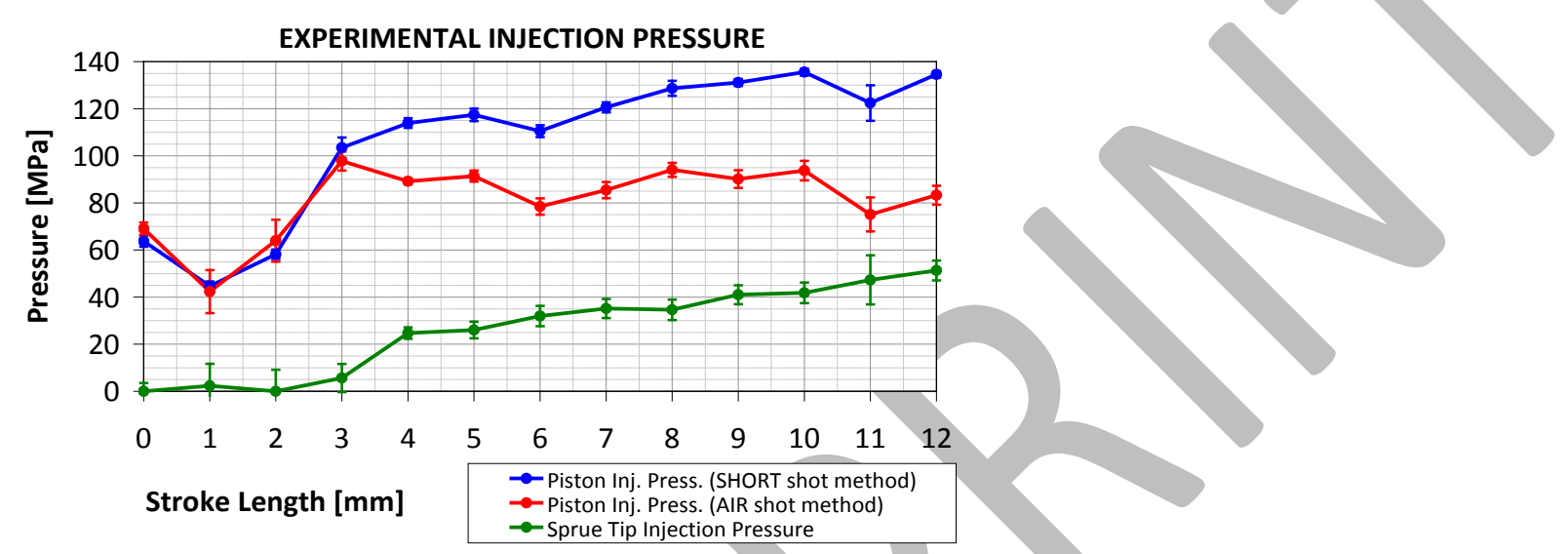

Figure 13 - Cavity (sprue tip) injection pressure calculation as difference between short shot and air shot piston injection pressure.

\section{Simulation set-up}

Simulations were run and 3D analysis meshes were prepared using the 2011 version of the Autodesk Moldflow Insight ${ }^{\circledR}$ product. From an IGES 3D CAD model of the geometry, a 3D volume mesh of tetrahedral elements was created using 1,000,000 elements and at least 10 element layers across all thickness cross sections (see Figure 9). An analysis sequence was selected which included filling, packing (including the cooling phase) and warpage calculations.

Accurate process control allows uncertainties and inaccuracies in the set-up phase of the simulation to be reduced. In particular, input regarding the filling control settings in the software should be consistently determined and defined to be implemented in the simulation set-up.

For the simulations of the dog-bone geometry, the "ram speed vs. ram position" setting was employed. This set-up was particularly suitable because it allowed the melt compressibility for the whole available stroke length (i.e. $23 \mathrm{~mm}$ ) to be taken into account by the software. In this way the behaviour of the machine could be reproduced by the software: a full $23 \mathrm{~mm}$ stroke of polymer melt prepared prior to injection, and a total volume injected in the cavity corresponding to a stroke of 12 $\mathrm{mm}$. The injection piston diameter $(3 \mathrm{~mm})$ was specified in the injection molding machine advanced option settings. A machine response time of $1 \mathrm{~ms}$ was set. This is shorter than the default value of $10 \mathrm{~ms}$ which is suitable for conventional injection molding machines.

From the experimental process monitoring, the actual piston velocity of $100 \mathrm{~mm} / \mathrm{s}$ was used for the whole stroke length. 
Experiments were performed with a packing phase of 3 seconds having zero pressure after switchover at $11 \mathrm{~mm}$ piston position (i.e. the difference between $23 \mathrm{~mm}$ for the full stroke and the $12 \mathrm{~mm}$ stroke length for a full part). In the simulation, this was implemented as a $3 \mathrm{~s}$ cooling time. Mold and melt temperatures were set in accordance to the average values recorded during the experiments.

\subsection{Dog-bone simulation and validation}

The simulation settings described in the previous section represented the basic information needed to run a successful simulation. From this, a sound validation study was conducted based on the quantitative comparison of simulation results with calibrated process measurements.

To assess the quality of the simulation results, the following parameters have been selected for the comparison: pressure at injection location (i.e. sprue tip injection pressure), short shot flow front pattern, short shot mass, short shot length. The results of these four comparisons are presented in the following sections.

\subsection{Validation of pressure prediction at the injection location}

The pressure at injection location (defined as sprue tip pressure as explained in section 3.1) determined by applying the air shot and short shot methods is compared with the simulated pressure at the injection location. The comparison was carried out on a quantitative basis taking into account experimental variation of the recorded pressure values as well as the stochastic error on the pressure determination method. Both the simulated and experimental pressures curves are presented in Figure 14. The comparison indicates good pressure agreement is achieved after $40 \mathrm{~ms}$ (i.e. flow front position at the gate, see Table 1) onwards. The injection pressure at the end of filling appears to approach the maximum experimental pressure. As far as time is concerned, the inexact agreement can be attributed to inaccuracy in the cavity injection time measurement and in the switch-over point determination of a few milliseconds: the simulated cavity injection time of 116 $\mathrm{ms}$ is $4 \mathrm{~ms}$, i.e. $3 \%$, shorter than the experimental measured value.

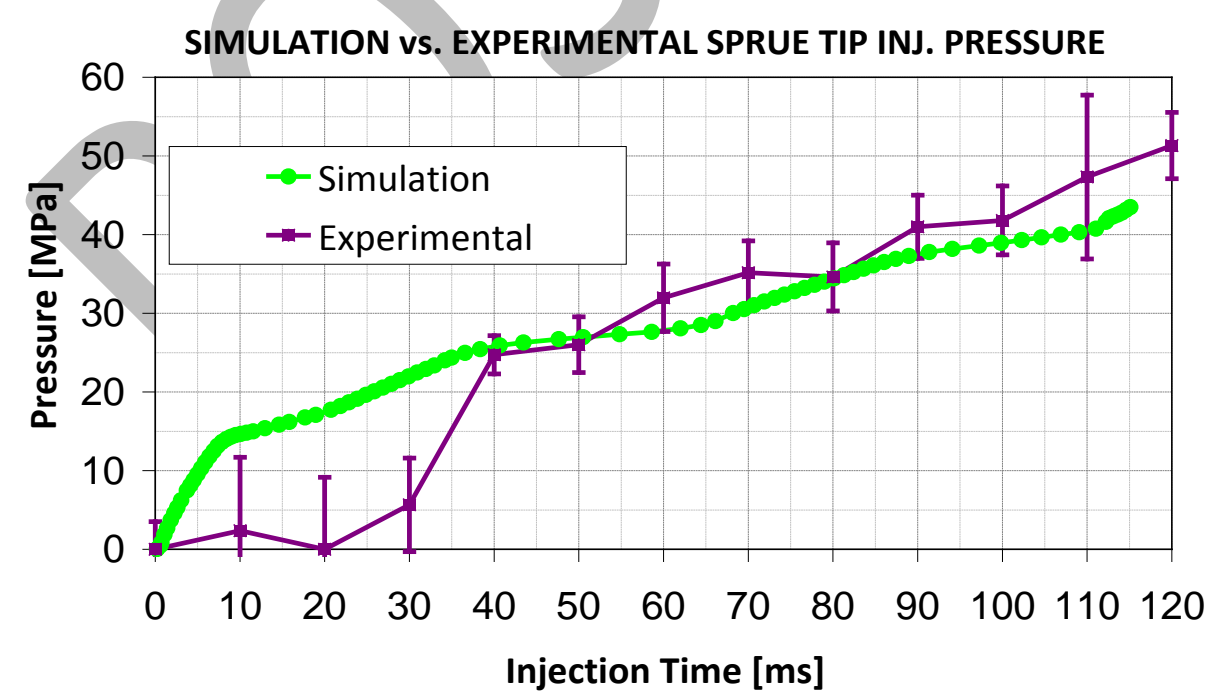

Figure 14 - Measured and simulated injection pressure comparison for validation study. 
The injection pressure comparison shown on the left side of Figure 14 shows a large discrepancy between simulation and experiment for the first $30 \mathrm{~ms}$. This difference can be explained by the existence of a jetting phenomenon initially occurring at the sprue location which is visible in the moldings of both the short shots and the air shots. A melt jet detachment during filling of the sprue can be observed in the actual experiments, whereas the simulation which used $100 \mu \mathrm{m}$ size elements predicts uninterrupted melt contact with the mold and a no-slip flow condition (see Figure 15). Therefore, an alternative simulation was run using $25 \mu \mathrm{m}$ size elements in the sprue volume and including an approximate modelling of the machine nozzle tip which is narrower than the top of the sprue. With this modified mesh, the jetting phenomenon was briefly visible at the beginning of the filling phase (see Figure 16). A comparison of the simulated injection pressure at the sprue tip was carried out between the two different meshed geometries. The appearance of jetting with the finer meshed model creates the conditions to simulate the effect of the delayed melt/tool surface contact (see Figure 17). As a consequence, a lower deviation between simulated and experimental results is observed, particularly for the first $12 \mathrm{~ms}$ of filling time.

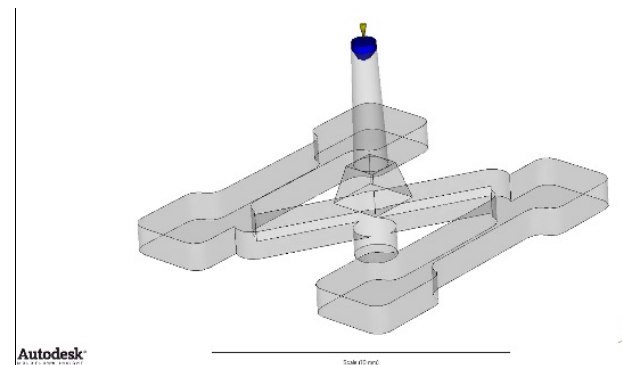

(a) Filling time $=1 \mathrm{~ms}$
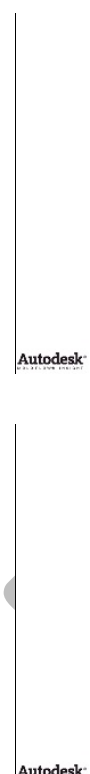

(e) Filling time $=7 \mathrm{~ms}$

(c) Filling time $=4 \mathrm{~ms}$
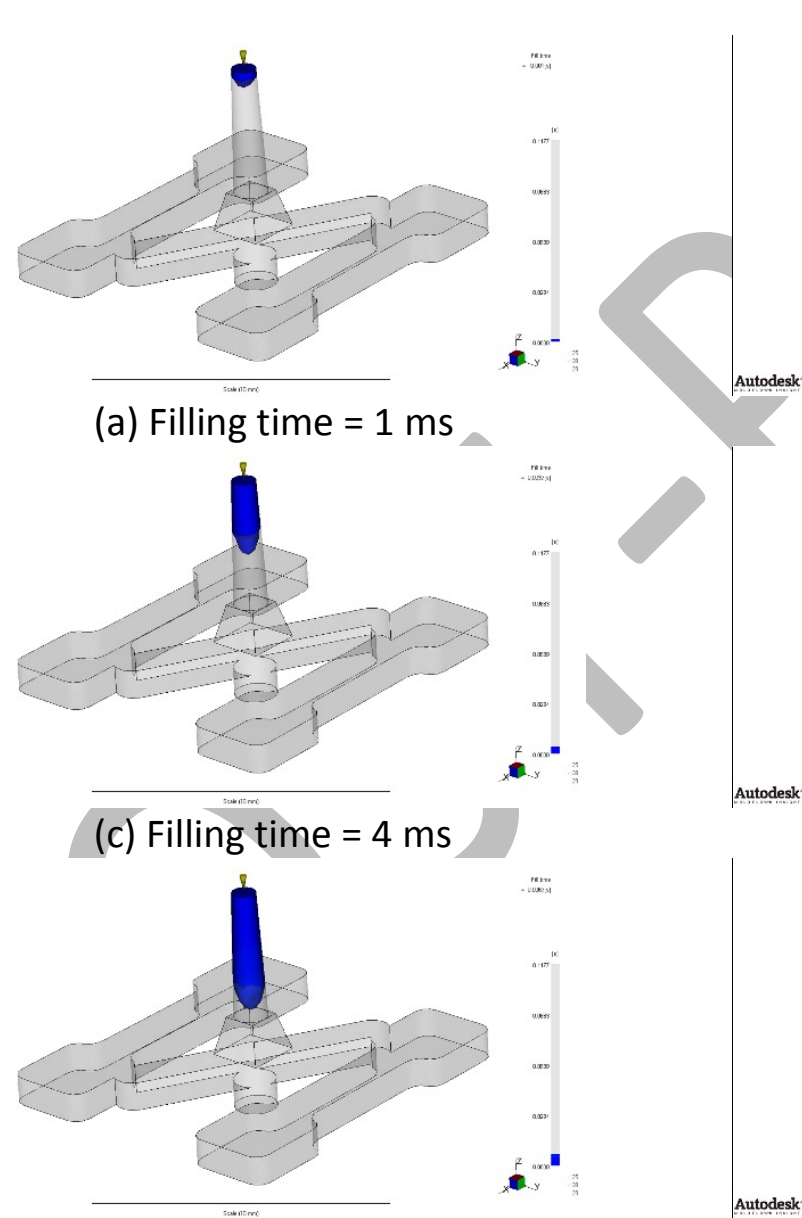

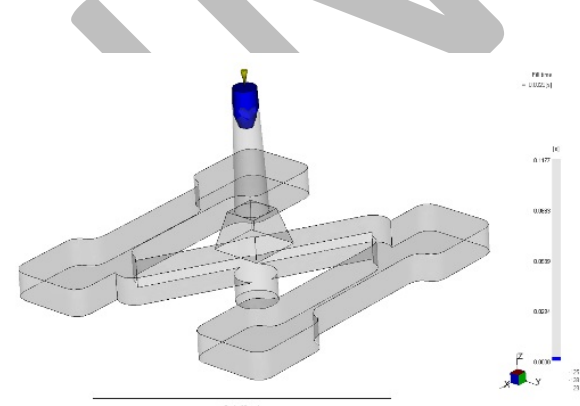

(b) Filling time $=2 \mathrm{~ms}$

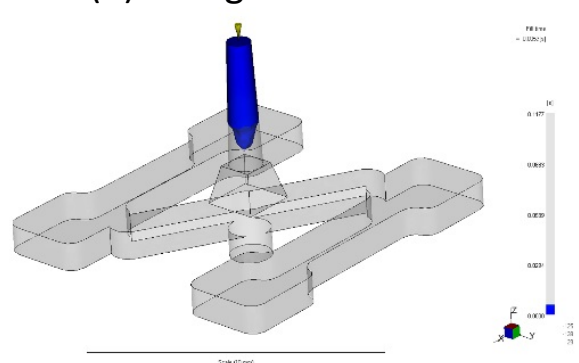

(d) Filling time $=6 \mathrm{~ms}$

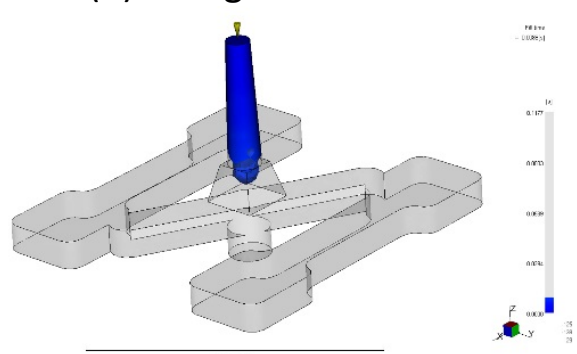

(f) Filling time $=9 \mathrm{~ms}$

Figure 15 - Simulation with $100 \mu \mathrm{m}$ size element mesh: complete contact between melt and tool surface in the sprue area is observed and no jetting phenomena is visible. 


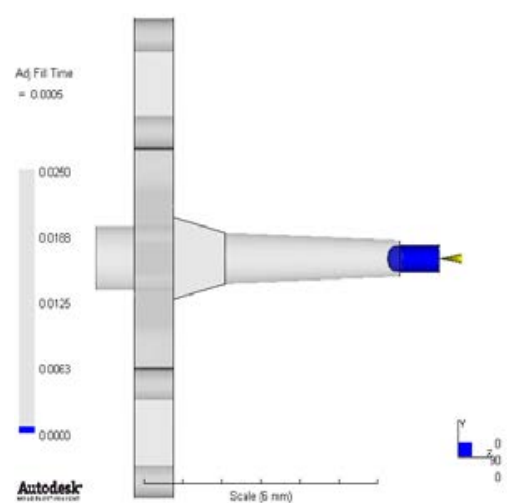

(a) Filling time $=1 \mathrm{~ms}$

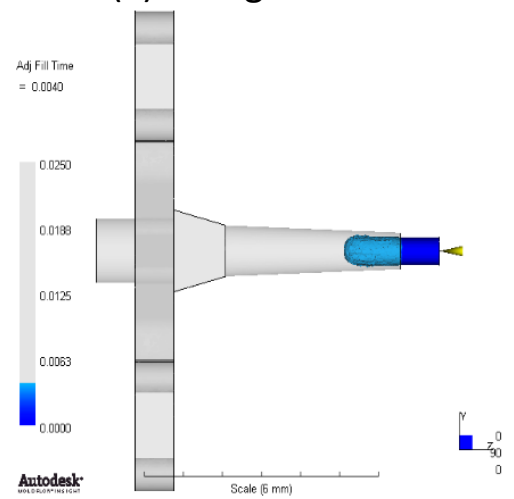

(c) Filling time $=4 \mathrm{~ms}$

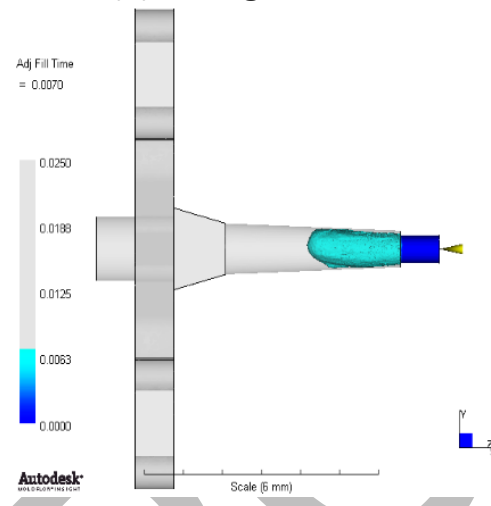

(e) Filling time $=7 \mathrm{~ms}$

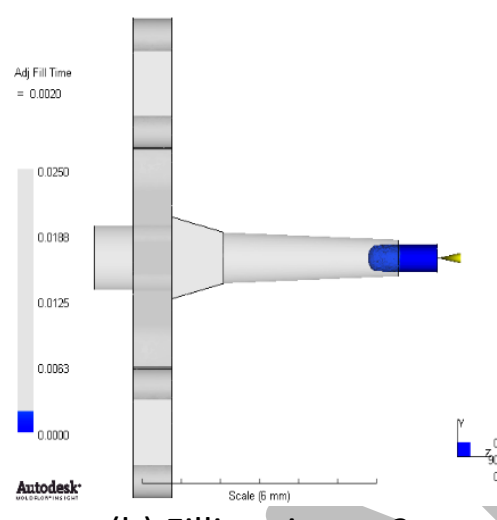

(b) Filling time $=2 \mathrm{~ms}$

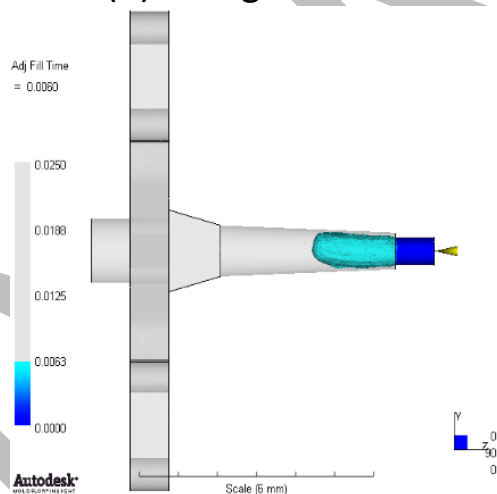

(d) Filling time $=6 \mathrm{~ms}$

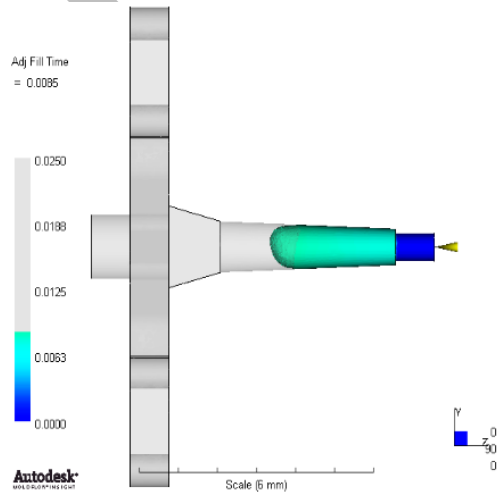

(f) Filling time $=9 \mathrm{~ms}$

Figure 16 - Simulation with $25 \mu \mathrm{m}$ size element mesh: the jetting phenomena is briefly simulated before complete contact between melt and tool surface in the sprue area is established. 
SIMULATION vS. EXPERIMENTAL INJECTION PRESSURE

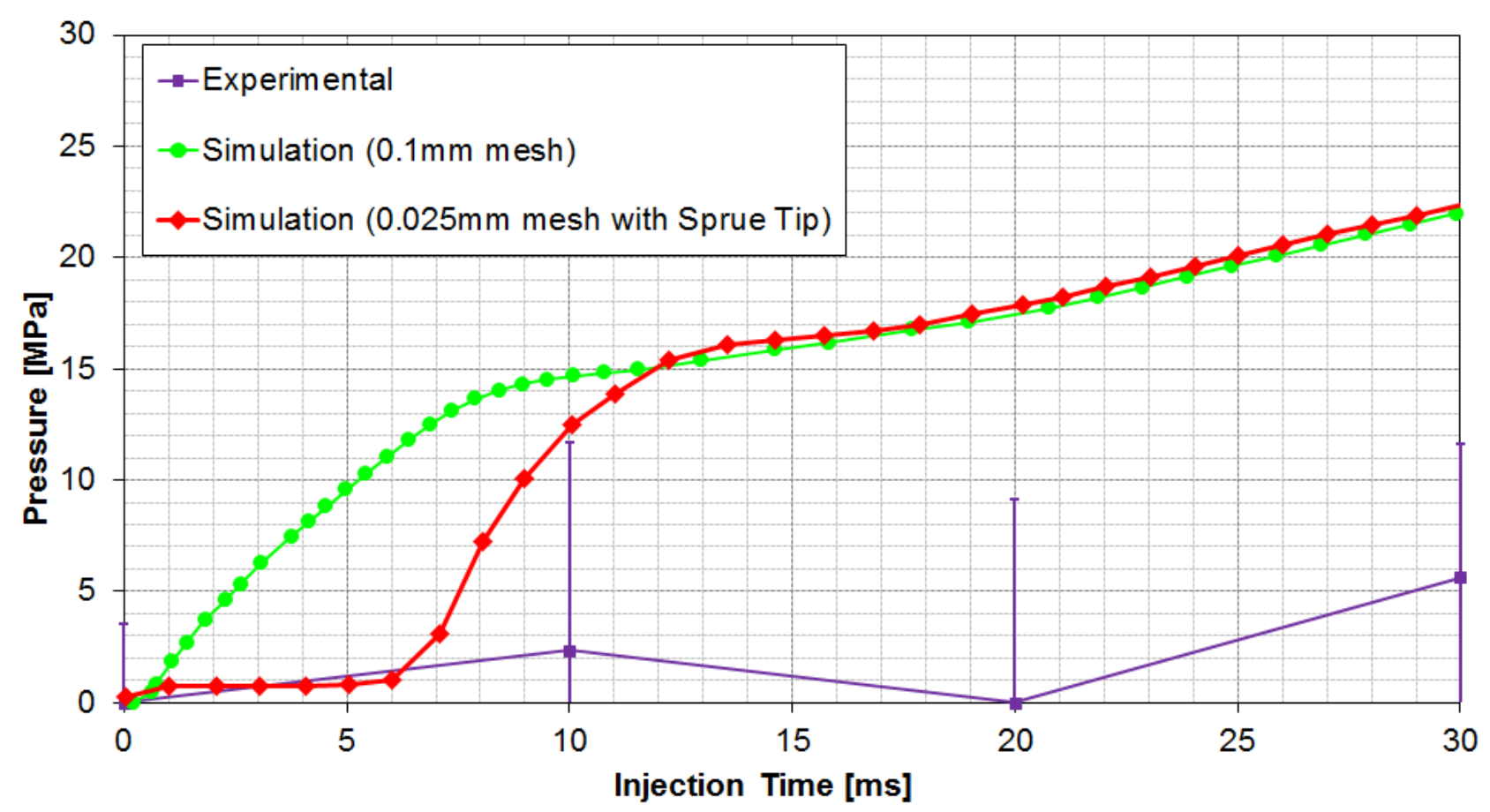

Figure 17 - Effect of jetting on the simulated injection pressure at sprue tip: the delayed melt/tool surface contact causes a decrease of predicted injection pressure during the first $12 \mathrm{~ms}$.

\subsection{Validation of flow front pattern, short shot mass and length simulation}

Intermediate steps of the filling time animation were collected at times corresponding to experimental short shots injection times. First, flow front position and pattern comparison between simulation and experiments is performed on a qualitative basis. Comparison between experimental and simulated short shots is shown in Table 1. The flow front pattern of experimental short shots was successfully simulated.

In particular, the role of including inertia in the Navier-Stokes calculation and its effect on the accuracy of flow front prediction was investigated. Inertia is the mass-velocity term in the momentum equations. This means that if fluid has a velocity, it will tend to keep that velocity, unless some other force acts upon it. Other forces can include the viscous forces (stresses) which derive from shear deformation. In the particular case of injection molding of polymers, the viscous stresses are very large compared to the inertia terms. This is due to the relatively high viscosity of polymer melt (compared to other fluids such as air) and the narrow cavities through which polymers are injected. The inertia option should be used when the Reynolds number is expected to be greater than 1 (i.e. inertia forces dominate as compared with viscous forces), when high simulation accuracy is required, when high velocities occur (e.g. in a small gate region) and narrow regions represent a relatively large contribution to the total injection pressure. All these conditions apply to the considered micro molding case. In particular, in the injection molding conditions of the current case (piston diameter $=3 \mathrm{~mm}$, piston speed $=100 \mathrm{~mm} / \mathrm{s}$, sprue tip diameter $=0.84 \mathrm{~mm}$, melt temperature $=220^{\circ} \mathrm{C}$ ), the following measures are determined: hydraulic diameter $d_{h}=0.84 \mathrm{~mm}$; density $\rho=$ 
$1.149 \mathrm{~g} / \mathrm{cm}^{3}$; velocity $v=1.28 \mathrm{~m} / \mathrm{s}$; dynamic viscosity $\eta=403 \mathrm{~Pa} \cdot \mathrm{s}$. Therefore, the Reynolds number at the sprue tip injection location is calculated as $\operatorname{Re}=\left(\rho \cdot v \cdot d_{h}\right) / \eta=3.1>1$, which confirms that the inertia effects should be taken into account and included in the calculation. A clear improvement of flow front prediction accuracy is obtained at the expenses of a longer calculation time. If the inertia term is removed from the momentum equations, the calculations are simplified and therefore some analysis speed improvement is achieved (analysis time saving up to 50\%) at the expense of accuracy. The filled volume is calculated at each time step and therefore it is possible to determine the mass for each short shot for direct comparison with the experiments at the corresponding injection times. Agreement in short shot mass between simulation (including inertia effects) and experiments was demonstrated, with an average relative deviation between simulations and experiments of $1.2 \%$ (see Figure 18 and Figure 19).

The short shot length of the molded parts was defined as the part length along the main flow direction in the dog-bone section. The same length definition was applied to the measurement of simulated short shots. A warpage analysis was performed in order to include the predicted change in part dimensions (deflection) due to shrinkage during cooling. The software can calculate the deflection projected along the $X, Y, Z$ directions. For the short shot length correction due to shrinkage, the deflection component along the $X$ direction calculated on the full part length (2.33\%) was taken into account and applied to all the intermediate steps. Agreement between simulated and measured lengths on the micro molded parts was found (see Figure 20) with deviations in the range from 50 to $600 \mu \mathrm{m}$, corresponding to $0.5 \%$ and $8.2 \%$ of the length (see Figure 21). Indeed, the final part length could be correctly predicted with a deviation of $0.06 \mathrm{~mm}$ (over a length of 11.761 $\mathrm{mm}$ ), which was in the same order of magnitude as the experimental repeatability (length standard deviation $=15 \mu \mathrm{m})$.

Table 1 - Validation of flow front pattern by comparison with experimental short shots. Different stages of simulated and experimental flow advancement are taken at corresponding injection times and then compared.

\begin{tabular}{|l|l|l|l|}
\hline $\begin{array}{l}\text { Injection } \\
\text { time }\end{array}$ & $\begin{array}{l}\text { Experimental short } \\
\text { shot }\end{array}$ & $\begin{array}{l}\text { Simulated short shot } \\
\text { with inertia effect }\end{array}$ & $\begin{array}{l}\text { Simulated short shot } \\
\text { without inertia effect }\end{array}$ \\
\hline $50 \mathrm{~ms}$ & $\mathrm{~ms}$ & $5 \mathrm{~mm}$ &
\end{tabular}




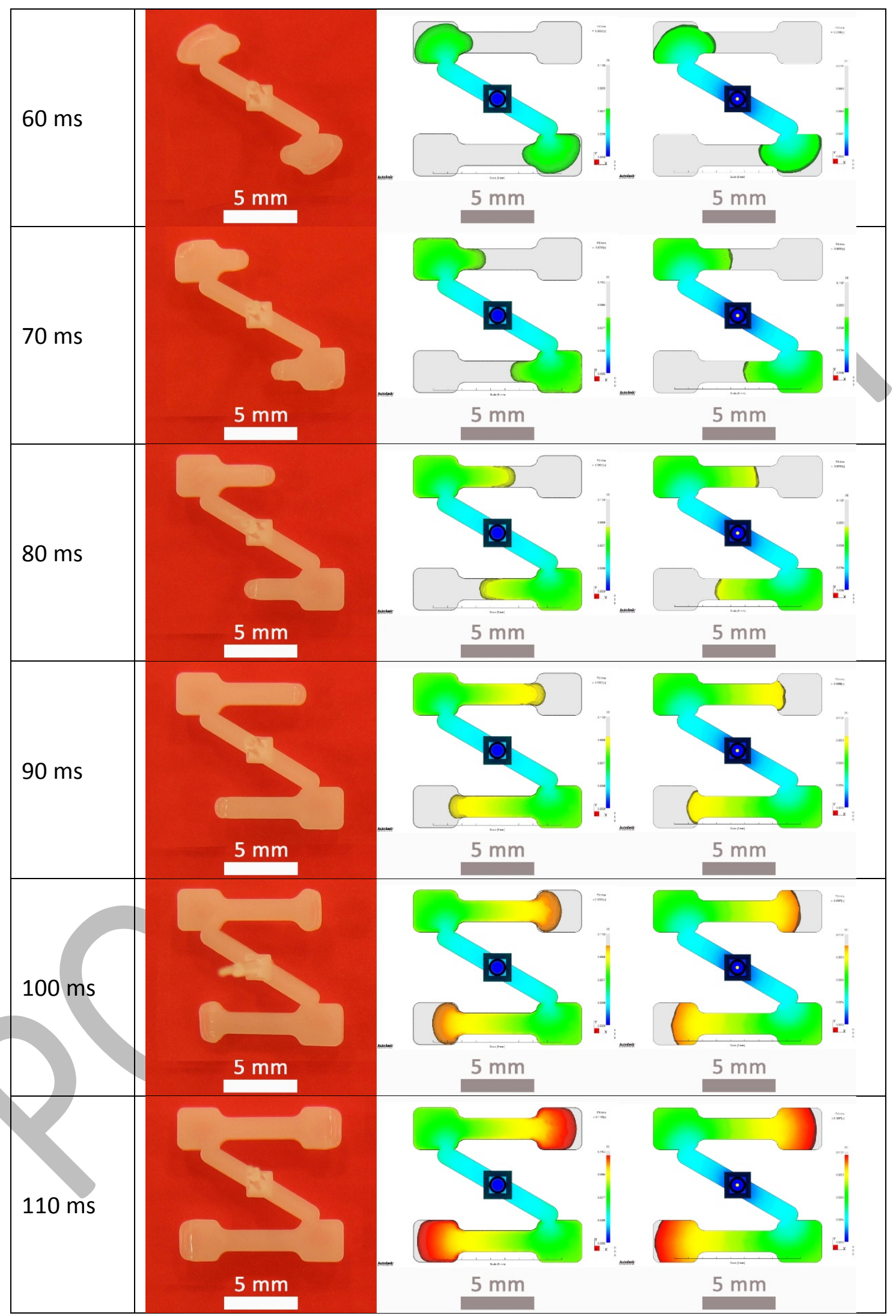



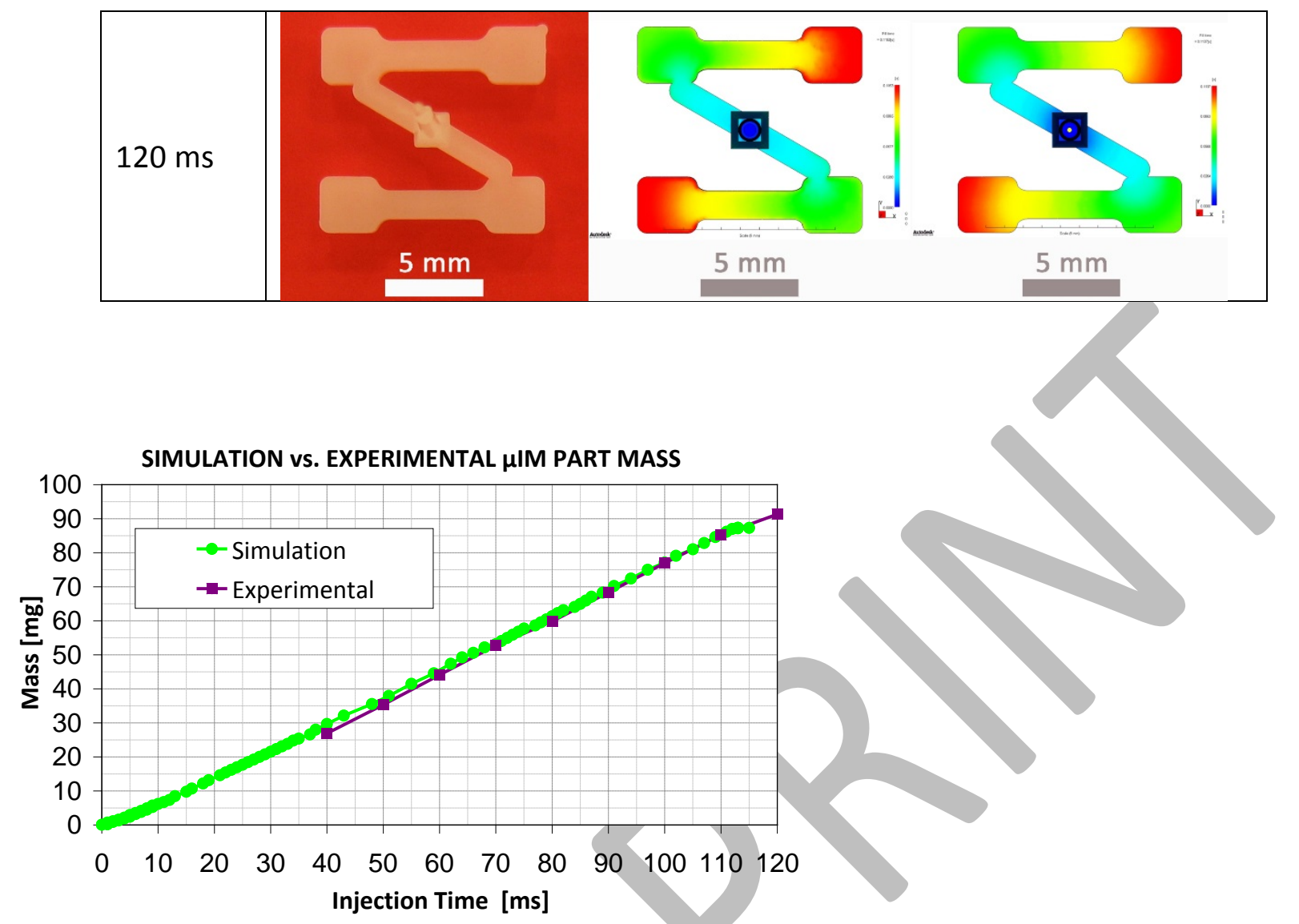

Figure 18 - Measured and simulated short shot (including inertia effect) mass comparison.

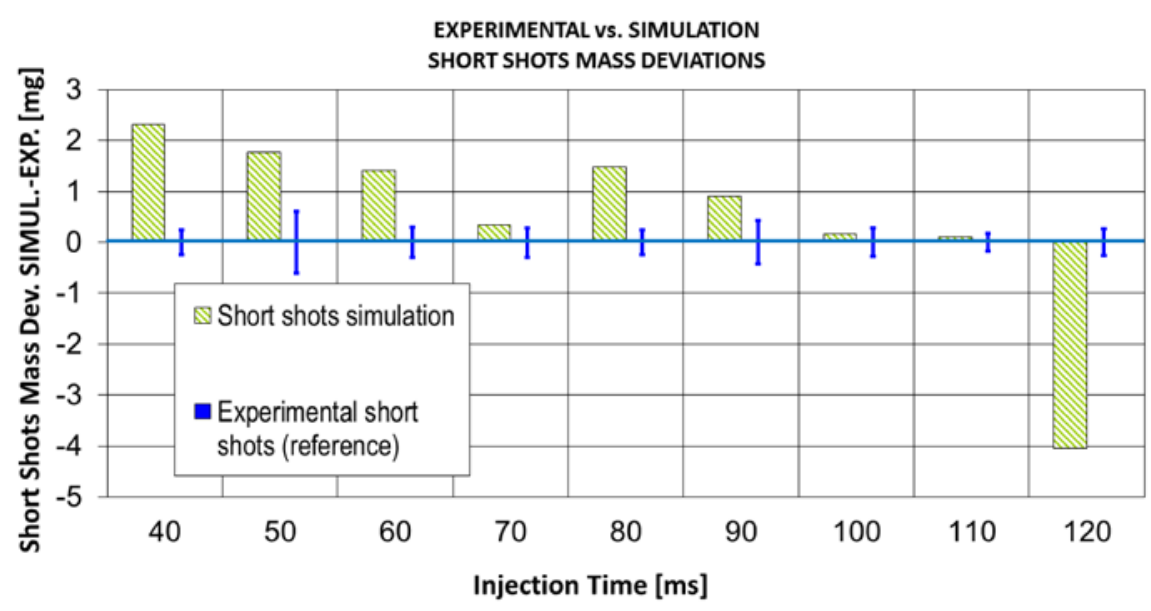

Figure 19 - Simulated short shot mass deviations (including inertia effect) from actual molded parts. Error bars on experimental results represent mass standard deviation over 10 micro injection molded parts for each short shot experiment. 


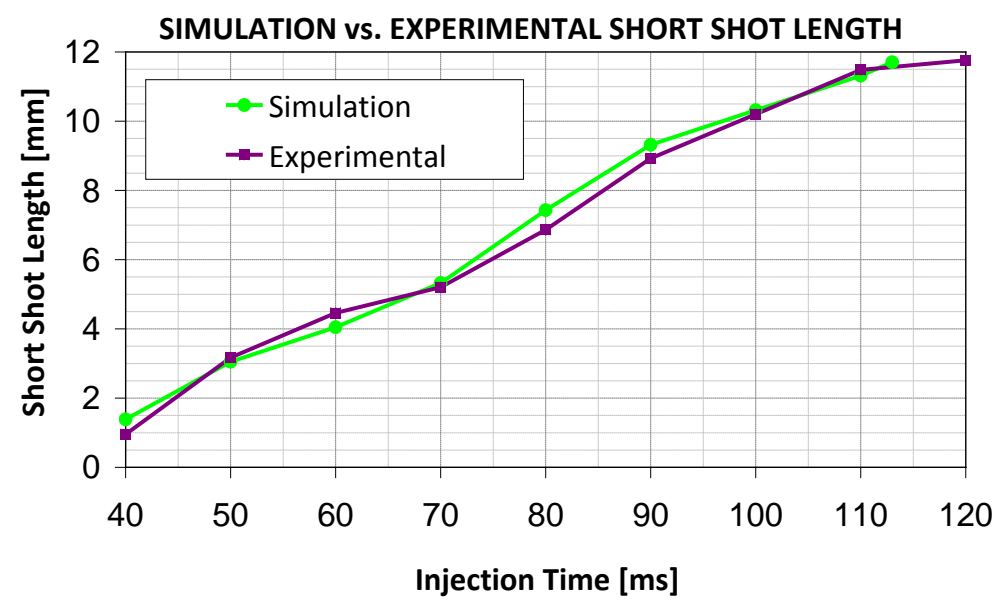

Figure 20 - Measured and simulated short shots (including inertia effect) length comparison.

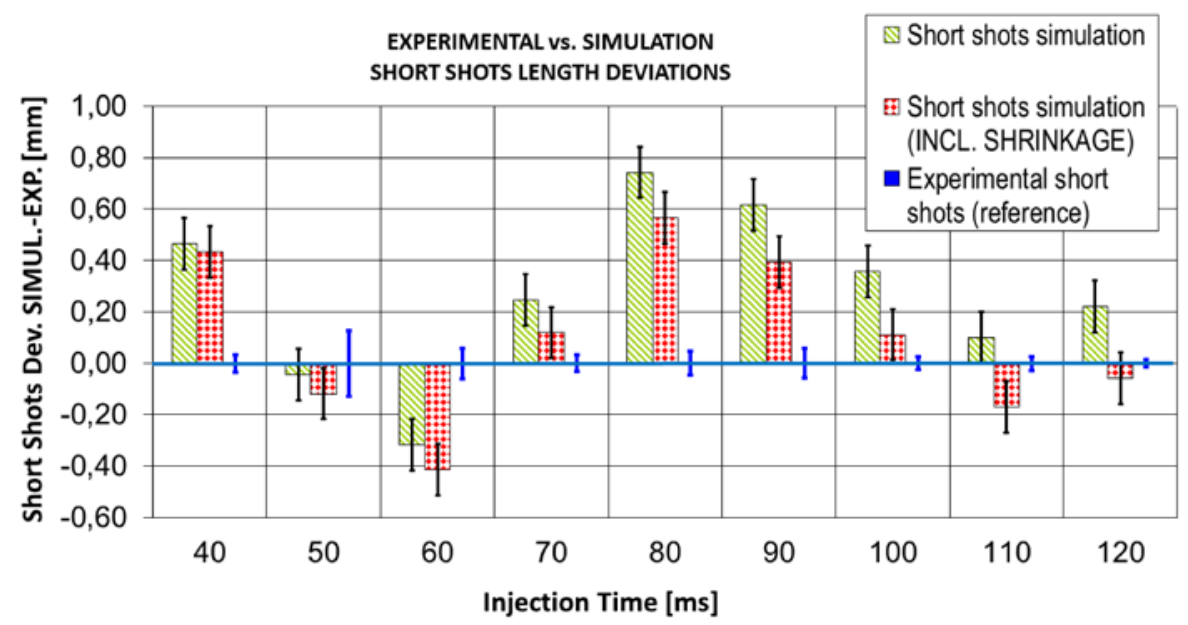

Figure 21 - Simulated short shot length deviations (including inertia effect) from actual molded parts. Error bars on experimental results represent length standard deviation of $\mathbf{1 0}$ micro injection molded parts for each short shot experiment. Error bars on simulated results represent an average mesh element length (100 $\mu \mathrm{m})$.

\section{Conclusion}

Simulations of injection pressure, filling pattern, short shot mass and short shot lengths of micro injection molding were performed. Experiments were carried out in controlled conditions applying process monitoring and product quality control techniques. Accurate measurements of the micro molded parts confirmed high process reliability and reproducibility. The simulation set-up was performed using accurate input data from the process in terms of melt and mold temperatures, cavity geometry and piston injection speed. Key features of a validation study for micro molding were investigated: the application and validity of the short shot method in micro injection molding, the use of micro moldings mass and injection times for process control validation, the role of micro molding machine geometry (nozzle and injection chamber) on simulation accuracy, and the use of simulated short shots derived from the filling time animation (i.e. results at intermediate filling times of a full stroke simulation) to validate short shot moldings. Agreement was found between simulation results and measured process data in terms of injection time, pressure at injection 
location (i.e. at the sprue tip position), flow front length and shape, and short shot mass and length. Further, jetting phenomenon at the sprue location was observed, investigated and eventually simulated. The crucial role of mesh size was analyzed and an improved injection pressure was calculated with an optimized simulation set-up.

High quality input data, a calibrated process, and an accurate mesh allowed the attainment of accurate simulation results. Therefore, the validation of micro molding simulation has been shown. The accuracy of simulative predictions obtained by applying the presented procedures demonstrates the potential of using numerical simulations as a tool to develop polymer micro products, micro molds and to optimize the micro injection molding process.

\section{Acknowledgments}

This paper reports work undertaken in the context of the project "COTECH" (Converging Technologies for Micro Systems Manufacturing, http://www.fp7-cotech.eu/), WP4.4 "Processes simulation" (COTECH is a Large Scale Collaborative Project supported by the European Commission in the 7th Framework Programme, Proposal number CP-IP 214491-2, 2008-2012) and of the project "ProSurf" (High Precision Process Chains for the Mass Production of Functional Structured Surfaces, http://www.prosurf-project.eu/), WP3.2 "Modelling and simulation of injection molding processes" (ProSurf is a Factory of the Future Research and Innovation Action supported by the European Commission in the Horizon 2020 Framework Programme, Proposal number 767589, 2018-2020). Dr. Patrick Guerrier, formerly at Technical University of Denmark, Department of Mechanical Engineering, is gratefully acknowledged for his contribution in connection with the preliminary study "Three-dimensional Simulations of Micro Injection Moulded Components" (2009). The collaboration of Mr. Bjoern Dormann and Mr. Christian Decker from DESMAtec (Achim, Germany), which kindly provided the micro injection molding machine, is gratefully acknowledged.

\section{References}

[1] M.J. Jaworski, and Z. Yuan, Proceedings of the 62nd Annual Technical Conference (ANTEC) of the Society of Plastic Engineers (SPE), (2003).

[2] B.R. Whiteside, M.T. Martyn, and P.D. Coates P.D., International Journal of Polymer Processing, 20, 5 (2005).

[3] M.N. Mehta, M.F.C. Barry, T.D. Bibber, and D. Tully, Proceedings of the 62nd Annual Technical Conference (ANTEC) of the Society of Plastic Engineers (SPE), (2003).

[4] X. Han, and H. Yokoi, Polymer Engineering and Science, 46, 11, (2006).

[5] L. Xie, and G. Ziegmann, Microsystems Technologies, 14, (2008).

[6] B.R. Whiteside, R. Spares, and P.D. Coates, Proceedings of the 68th Annual Technical Conference (ANTEC) of the Society of Plastic Engineers (SPE), (2009).

[7] G. Tosello, A. Gava, H.N. Hansen, and G. Lucchetta, International Journal of Advanced Manufacturing Technology, 47, 1-4, (2010).

[8] A. Gava, G. Tosello, G. Lucchetta, H.N. Hansen, and M. Salvador, 9th International Conference on Numerical Methods in Industrial Forming Processes (NUMIFORM), (2007).

[9] D. Delaunay, and P. Le Bot, Polymer Engineering and Science, 40, 7, (2000).

[10] O. Kemann, L. Weber, C. Jeggy, O. Magotte and F. Dupret, Proceedings of the 59th Annual Technical Conference (ANTEC) of the Society of Plastic Engineers (SPE), (2000).

[11] L. Yu, L. J. Lee, and K.W. Koelling, Polymer Engineering and Science, 44, 10, (2004). 
[12] T. Nguyen-Chung, G. Jüttner, C. Löser, T. Pham, and M. Gehde, Polymer Engineering and Science, 50, 1, (2010)

[13] H. Takahashi, T. Matsuoka, and T. Kurauchi, Journal of Applied Polymer Science, 30, pp. 4669-4684 (1985).

[14] A.L. Kelly, T. Gough, B.R. Whiteside, and P.D. Coates, Journal of Applied Polymer Science, 114, (2009).

[15] A. Haddout, and G. Villoutreix, International Polymer Processing, 15, (2000).

[16] R.D. Chien, W.R. Jong, and S.C. Chen, Journal of Micromechanics and Microengineering, 15, 8, (2005).

[17] W. Cao, O. Hassager, and Y. Wang, Proceedings of the Polymer Processing Society (PPS) 24th Annual Meeting, (2008).

[18] P. Kennedy, Flow Analysis of Injection Molds. Hanser (1995). Munich, Germany.

[19] C.A. Hieber, and S.F. Shen, Journal of Non-Newtonian Fluid Mechanics, 7, (1980).

[20] U. Vietri, A. Sorrentino, V. Speranza, and R. Pantani, Polymer Engineering and Science, Vol. 51, (2011).

[21] Joint Committee for Guides in Metrology, Guide to the Expression of Uncertainty in Measurement (GUM), (2008). 